\title{
Heparin-binding Secretory Transforming Gene (hst) Facilitates Rat Lactotrope Cell Tumorigenesis and Induces Prolactin Gene Transcription
}

\author{
Ilan Shimon, ${ }^{\star}$ Anita Hüttner, ${ }^{*}$ Jonathan Said, ${ }^{\ddagger}$ Olga M. Spirina, ${ }^{\star}$ and Shlomo Melmed \\ Departments of*Medicine and ${ }^{\ddagger}$ Pathology, Cedars-Sinai Research Institute, UCLA School of Medicine, Los Angeles, California 90048
}

\begin{abstract}
We have shown previously that human prolactinomas express transforming sequences of the heparin-binding secretory transforming gene (hst) which encodes fibroblast growth factor-4 (FGF-4). To elucidate the role of $h s t$ in pituitary tumorigenesis we treated primary rat pituitary and pituitary tumor cell cultures with recombinant FGF-4 and also stably transfected pituitary cell lines with full-length human hst cDNA. Transfectants were screened for hst mRNA expression and FGF-4 production. FGF-4 (0.1-50 $\mathrm{ng} / \mathrm{ml}$ ) caused a dose-dependent 2.5 -fold increase of prolactin (PRL) secretion $(P<0.001)$ in GH4 cells and up to $60 \%$ $(P<0.05)$ in primary cultures, while decreasing growth hormone release $(P<0.001)$. GH4 hst transfectants displayed markedly enhanced basal PRL secretion (threefold, $P<0.001)$ and also proliferated faster $(P<0.001)$. FGF-4 treatment of wild-type GH4 cells, transiently transfected with an expression construct (rPRL.luc) containing a luciferase reporter driven by the rPRL promoter, resulted in a dose-dependent increase of up to 3.3-fold in PRL transcriptional activity. Tumors derived from in vivo subcutaneous injection of GH4 hst-transfected cells strongly expressing FGF-4 grew more aggressively as assessed by histologic invasiveness and proliferating cell nuclear antigen staining $(P<$ 0.01). The results indicate that hst overexpression mediates lactotrope tumor growth and potently stimulates PRL synthesis. Thus, hst may directly facilitate prolactinoma development via paracrine or autocrine action of its secreted protein, FGF-4. (J. Clin. Invest. 1996. 97:187-195.) Key words: prolactinoma - pituitary adenoma - growth factor $\bullet$ fibroblast growth factor-4
\end{abstract}

\section{Introduction}

Tumors of the anterior pituitary arise from adenohypophyseal cell types expressing trophic hormone gene products (1). These monoclonal neoplasms $(2,3)$ may be either functional or nonfunctional, depending on the differentiated secretory pattern of the tumor cell of origin. Recently, several lines of evidence have indicated an intrinsic genetic defect in these tumors, leading to cellular proliferation often accompanied by

Address correspondence to Shlomo Melmed, M.D., Division of Endocrinology and Metabolism, Cedars-Sinai Medical Center, 8700 Beverly Blvd., B131, Los Angeles, CA 90048. Phone: 310-855-4691; FAX: 310-967-0119; E-mail: Melmed@CSMC.edu

Received for publication 20 July 1995 and accepted in revised form 27 September 1995.

J. Clin. Invest.

(c) The American Society for Clinical Investigation, Inc.

0021-9738/96/01/0187/09 \$2.00

Volume 97, Number 1, January 1996, 187-195 unrestrained hormone secretion. Somatic mutations of G-protein signaling have been reported in a subset of growth hormone $(\mathrm{GH})$-secreting ${ }^{1}$ pituitary tumors (4). However, the nature of events leading to initiation or progression of prolactin (PRL)-secreting tumors is largely unknown. Loss of heterozygosity in the $11 \mathrm{q} 13$ chromosomal locus, the site that probably contains the putative tumor suppressor gene for multiple endocrine neoplasia type 1 (MEN-1), has been reported in a few cases of sporadic prolactinomas (5-7), but no specific inactivating mutation has been identified in these tumors.

The heparin-binding secretory transforming gene (hst), first identified as a transforming gene in DNA from human stomach cancer (8), encodes fibroblast growth factor-4 (FGF-4), a 206-amino acid protein. This growth factor belongs to the FGF family, which comprises proteins from at least nine distinct genes $(9,10)$. Unlike the two prototypes of this gene family, basic (FGF-2) and acidic FGF (FGF-1), FGF-4 contains an intact signal peptide, characteristic of secreted proteins, and is glycosylated and secreted in the medium of producer cells (11). The hst genomic fragment $(6.2 \mathrm{~kb})$ possessing transforming activity was sequenced $(12,13)$ and mapped to chromosome 11q13 (14). Subsequently the gene was isolated in Kaposi's sarcoma $(15,16)$, melanoma $(17)$, embryonal carcinoma (18), and several other solid malignant tumors (19-21). hst overexpression stimulates fibroblast proliferation, may induce a transformed phenotype (22), and plays a critical role in postimplantation development (23) and limb-bud differentiation (24). Like other members of the FGF family, hst possesses heparin-binding sites, and stability of the secreted protein is enhanced by heparin (25). hst expression is restricted to cells in the early stages of development, and normal adult tissue does not express the gene. Therefore, the constitutive expression of this gene appears to be associated with oncogenic transformation, except during embryogenesis and development.

Basic FGF (FGF-2) is present in bovine pituitary $(26,27)$ and in human pituitary adenomas (28). This growth factor stimulates PRL secretion from normal rat pituitary cells (29) and from cultured human pituitary adenomas (30) without affecting cell proliferation. Circulating basic FGF-like immunoreactivity was also reported in patients with MEN-1 and pituitary tumors $(31,32)$. The elevated immunoreactive FGF-2 levels decreased after surgical or medical therapy of the pituitary tumors (32).

Recently, we have isolated human prolactinoma hst gene sequences possessing transforming activity in an NIH 3T3 assay (33) and we also showed expression of $h s t$ mRNA in four prolactinomas using reverse PCR and a ribonuclease protection assay (33). Heretofore, hormonal effects of the hst gene

1. Abbreviations used in this paper: GH, growth hormone; hst, heparin-binding secretory transforming gene; MEN-1, multiple endocrine neoplasia type 1; PCNA, proliferating cell nuclear antigen; PRL, prolactin; TRH, thyrotropin-releasing hormone; WT, wild-type. 
product have not been described. To elucidate the role of $h s t$ in prolactinoma pathogenesis we now report the morphologic, mitogenic, and transcriptional effects of the transfected hst protooncogene. We studied the direct effect of the hst protein on rat primary pituitary cells and on GH- and PRL-secreting pituitary cell lines. The results demonstrate marked induction of PRL gene transcription and hormone secretion by hst as well as profound permissive effects on in vivo lactotrope tumor pathogenesis.

\section{Methods}

Cells and culture. Rat pituitary tumor cells GC (producing GH) and GH4 (producing both GH and PRL) were supplied by the American Type Culture Collection (Rockville, MD). Cells were cultured in DME (1 gram/liter glucose for GC cells, 4.5 grams/liter for GH4) containing $10 \%$ FBS, $2 \mathrm{mM}$ glutamine, and penicillin/streptomycin. Cells were treated with human recombinant FGF-4 protein $(\mathrm{mol} \mathrm{wt}=$ 17,000; R \& D Systems, Inc., Minneapolis, MN) in 6-well tissue culture plates $\left(10^{5}\right.$ cells $/$ well $)$ up to $50 \mathrm{ng} / \mathrm{ml}\left(3 \times 10^{-8} \mathrm{M}\right), 6$ wells for each dose in serum-free defined medium containing $0.2 \%$ BSA, 120 $\mathrm{nM}$ transferrin, $100 \mathrm{nM}$ hydrocortisone, $0.6 \mathrm{nM}$ triiodothyronine, $5 \mathrm{U} /$ liter insulin, $3 \mathrm{nM}$ glucagon, $50 \mathrm{nM}$ parathyroid hormone, $2 \mathrm{mM}$ glutamine, $15 \mathrm{nM}$ EGF, and penicillin/streptomycin. After incubations, medium was collected for assay, and cells were trypsinized for counting using a Coulter Counter (Coulter Electronics Inc., Hialeah, FL).

Primary rat pituitary cell culture. Anterior pituitaries were harvested from 11-wk-old female Wistar-Furth rats (Harlan Sprague Dawley Inc., Indianapolis, IN) after $\mathrm{CO}_{2}$ killing and decapitation. Specimens were washed carefully in DME supplemented with $0.3 \%$ BSA, then minced, and enzymatically dissociated using $0.35 \%$ collagenase and $0.1 \%$ hyaluronidase (both from Sigma Chemical Co., St. Louis, MO). Cell suspensions were filtered and resuspended in low glucose DME supplemented with $10 \%$ FBS, 2 mM glutamine, and antibiotics after washing. For primary cultures, $\sim 10^{6}$ cells were seeded in 6-well tissue culture plates, and $24 \mathrm{~h}$ later medium was changed to serum-free defined, when the attached cells in half of the wells were treated with $50 \mathrm{ng} / \mathrm{ml} \mathrm{FGF-4.}$

Hormone assays. RIA for rat GH and PRL were performed in duplicate, using reagents provided by the National Hormone and Pituitary Agency, National Institute of Diabetes and Digestive and Kidney Diseases (Bethesda, MD). Iodination of GH and PRL (5 $\mu \mathrm{g})$ with iodine-125 $(500 \mu \mathrm{Ci})$ (New England Nuclear, Boston, MA) mixed with $0.1 \mathrm{mg}$ Iodo-Gen (Pierce, Rockford, IL) was performed using 10-ml columns prepared by G-75 Sephadex (Sigma Chemical Co.).

Molecular cloning. The full-length human hst cDNA $(3.15 \mathrm{~kb})$ (11), kindly provided by Dr. Hiromi Sakamoto, was inserted into the HindIII site of the pcDNA3 expression vector $(5.4 \mathrm{~kb})$ (Invitrogen, San Diego, CA) between the CMV promoter and the bovine GH poly(A). The cloned vector was sequenced by the Sanger method (34) to confirm the cDNA orientation and the correct hst encoding sequence (open reading frame 1 containing three exons and $618 \mathrm{bp}$ ) (11).

Cell transfection. GC and $\mathrm{GH} 4$ stable transfections with the cloned $h s t$ cDNA were performed in $3.5-\mathrm{cm}$ culture dishes $\left(1-2 \times 10^{5}\right.$ cells, $15-20 \%$ confluency).Transfection with $4 \mu \mathrm{g}$ linearized plasmid (by PvuI) using lipofectin (Gibco Laboratories, Grand Island, NY) $(10 \mu \mathrm{g} / \mathrm{dish})$ was performed in DME without serum for $24 \mathrm{~h}$ (35). GC and GH4 cells transfected with the original linearized pcDNA3 expression vector served as controls. Cells were diluted 1:10 and selected for 2 wk in G418 (Geneticin; Gibco Laboratories) (400 mg/liter for GC cells; $600 \mathrm{mg} /$ liter for GH4). Selected clones were subcultured before screening for mRNA expression and protein production.

Northern analysis of $G C$ and GH4 mRNA. Total cell RNA was extracted from cell cultures $\left(\sim 3 \times 10^{7}\right.$ cells/group) and from excised rat subcutaneous tumors (after tissue homogenizing) with TRIzol (Gibco Laboratories) (36). As a positive control we used RNA ex- tracted from the F9 embryonal carcinoma cell line (37) provided by the American Type Culture Collection. Isolated RNA was precipitated, washed, and denatured as described (38). Separated RNA was transferred to Hybond-N nylon membrane (Amersham International, Buckinghamshire, United Kingdom). The membrane was cross-linked, washed, prehybridized at $68^{\circ} \mathrm{C}$, and hybridized with $\sim 10^{7} \mathrm{cpm}{ }^{32} \mathrm{P}$-labeled human $h s t \mathrm{cDNA}$ in the presence of $100 \mu \mathrm{g} / \mathrm{ml}$ salmon sperm DNA (Stratagene, La Jolla, CA). Human hst cDNA (618 bp) was kindly provided by Dr. Sakamoto. A 285-bp fragment, spanning the $3^{\prime}$ half of the hst cDNA encoding region, was labeled with $\left[\alpha{ }^{32} \mathrm{P}\right] \mathrm{dATP}$ and dCTP using Klenow enzyme (Boehringer Mannheim, Indianapolis, IN). Posthybridization washes were followed by air drying and exposure to x-ray film (Fuji, Kanagawa, Japan) at $-80^{\circ} \mathrm{C}$.

hst immunoprecipitation. WT (wild-type) and transfected cells were labeled for $4 \mathrm{~h}$ by addition of $500 \mu \mathrm{Ci}$ of $\left[{ }^{35} \mathrm{~S}\right]$ methionine and cysteine (Express Labeling Mix; New England Nuclear) to DME (depleted of these amino acids) containing $10 \%$ FBS and antibiotics. After labeling, cells were washed with PBS and trypsinized, and total cell extract was prepared by lysis (39) and immunoprecipitated with 8 $\mu \mathrm{g} / \mathrm{ml}$ mouse anti-human FGF-4 monoclonal antibody (R \& D Systems, Inc.) at $4^{\circ} \mathrm{C}$ overnight. Immune complexes were recovered by association with $40 \mu \mathrm{l}$ protein $\mathrm{A}-\mathrm{Sepharose}$ (Pharmacia Fine Chemicals, Uppsala, Sweden) at $4^{\circ} \mathrm{C}$ for $3 \mathrm{~h}$, washed five times with lysis buffer, and denatured $\left(3 \mathrm{~min}, 100^{\circ} \mathrm{C}\right)$ in loading buffer. The gel was fixed, washed twice in water for $15 \mathrm{~min}$, and dried.

Transfected cell studies. Transfected GC and GH4 cells expressing $h s t$ mRNA were plated in 6-well tissue culture plates $\left(10^{5}\right.$ cells/ well) and grown in $1.5 \mathrm{ml}$ DME containing 10\% FBS and G418 (400 and $600 \mathrm{mg} /$ liter, respectively). After $48 \mathrm{~h}$ of incubation, cell morphology, cell counts, and medium GH and PRL levels were compared with WT cells (grown in DME containing FBS and penicillin/streptomycin) and to GC and GH4 cells transfected with the original pcDNA3 expression vector alone (grown in DME with serum and G418).

Luciferase assay. The reporter constructs pA3.luc containing the luciferase reporter gene (promoterless construct), pA3-425rPRL.luc (rPRL promoter) with the 498-bp fragment encompassing positions -425 to +73 of the rPRL gene ligated upstream of the reporter gene in pA3.luc, and pA3-rGH.luc (rGH promoter) containing the 593-bp fragment of the -528 to +65 region of the $\mathrm{rGH}$ gene were kindly provided by Dr. Arthur Gutierrez-Hartmann. Transient transfections of GH4 cells with one of these three plasmids $(4 \mu \mathrm{g}$ unlinearized DNA/dish) were performed by lipofectin $(20 \mu \mathrm{g} / \mathrm{dish})$ in $5 \mathrm{ml} \mathrm{DME}$ without serum for $16 \mathrm{~h}$. For each construct we transfected 12 dishes $\left(10^{6} \mathrm{cells} / \mathrm{dish}\right)$, and $24 \mathrm{~h}$ later, after the medium was changed to serum-free defined, half of the dishes in each transfection group were treated as depicted. GH gene regulation by FGF-4 was also tested in GC cells transiently transfected by the pA3-GH.luc construct. Luciferase activity was quantified in the treated and untreated wells as described previously (40). Luciferase activity was determined by adding cell extract ( $30 \mu \mathrm{g}$ protein) to $100 \mu \mathrm{l}$ of $1 \mathrm{mM}$ luciferin (Analytical Luminescence Laboratories, San Diego, CA) and light emission integrated over $15 \mathrm{~s}$ using an Auto Lumat LB 953 Luminometer (Berthold, Wildbad, Germany).

In vivo tumorigenesis. Cells transfected with the cloned construct and the original vector alone were detached from culture plates using $0.5 \mathrm{mM}$ EDTA in PBS and immediately injected $\left(10^{6}\right.$ cells in $0.2 \mathrm{ml}$ medium) subcutaneously into 4-5-wk-old female Wistar-Furth rats (80-95 grams) (Harlan Sprague Dawley Inc.). The use of rats was approved and followed guidelines outlined by the Institutional Animal Care and Use Committee. Rats were housed in pairs in an environment of controlled light/darkness (light on, 0600-1800 h) and temperature $\left(22 \pm 1^{\circ} \mathrm{C}\right)$ and had free access to food and water. Rats were checked weekly for tumor formation in the injection sites, weights were compared, and blood was collected retroorbitally $(0.4 \mathrm{ml})$ for hormone assays. Vaginal smears, taken daily at $1000 \mathrm{~h}$, were assessed microscopically for cytologic evidence of ovulation (41). $5 \mathrm{wk}$ after in- 
A

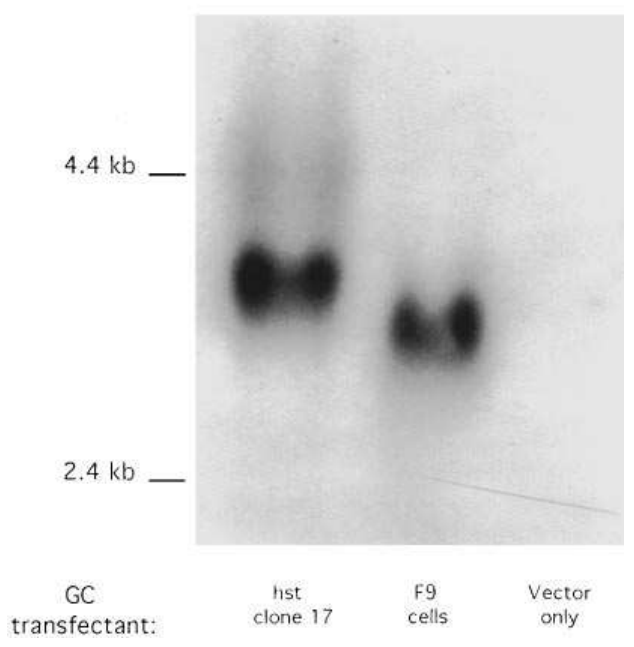

B

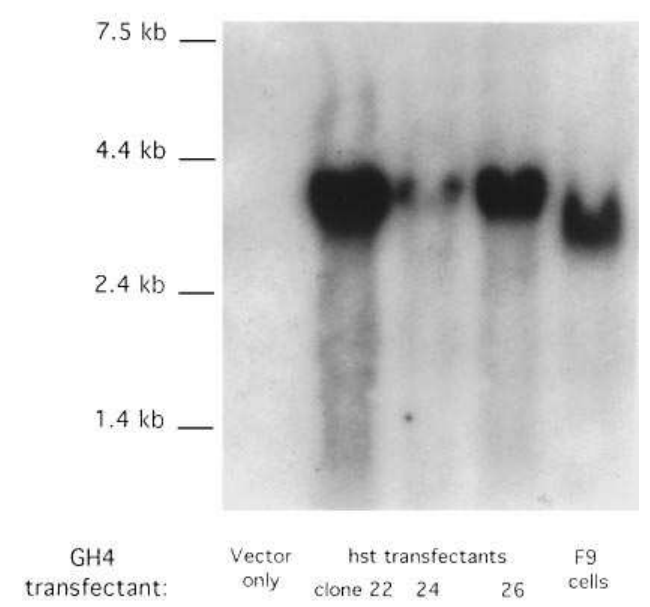

Figure 1. Northern blot of human hst mRNA expression in cells stably transfected with human $h s t$ cDNA. Extracted RNA (20 $\mu \mathrm{g} /$ lane) was separated by electrophoresis in $1 \%$ agarose gel, transferred to nylon membrane, and subjected to Northern hybridization with ${ }^{32} \mathrm{P}$ labeled $\left(\sim 10^{7} \mathrm{cpm}\right)$ 285-bp fragment spanning the $3^{\prime}$ half of $h s t$ cDNA encoding sequence. RNA extracted from F9 mouse embryonal carcinoma cells served as a positive control. $(A) \mathrm{GC}$ cells. (B) GH4 cells. A 3.6-kb mRNA transcript was demonstrated in $h s t$ transfectants (both GC and GH4), but not in cells transfected with the original vector (negative control). F9 cells express a $3.3-\mathrm{kb}$ hst transcript. jection, rats were killed, and tumors were dissected and weighed. Tissue for RNA extraction was immediately frozen to $-70^{\circ} \mathrm{C}$, and rats were examined for abdominal metastatic spread. $5-\mu \mathrm{m}$ sections from formaldehyde-fixed paraffin-embedded tissue blocks were used to assess histological differences in tumor invasiveness, and immunostaining for FGF-4, PRL, and proliferating cell nuclear antigen (PCNA) $(42,43)$. Immunohistochemical localization of FGF-4 was performed using immunoperoxidase staining as described previously (44). Mouse monoclonal antibody to human FGF-4 was obtained from R \& D Systems, Inc. and optimal dilution (1:30) determined by checkboard titration. Positive controls consisted of a similarly fixed F9 embryonal carcinoma cell pellet, and for negative controls primary antibody was replaced by isotype specific non-cross-reacting monoclonal antibody. After incubation with anti-FGF-4 antibody, slides were incubated sequentially with peroxidase-conjugated rabbit antimouse immunoglobulin and peroxidase-conjugated swine anti-rabbit immunoglobulin antibodies (both from Dako Corp., Carpinteria, CA). Antibody localization was affected by the peroxidase reaction using 3,3' diaminobenzidene hydrochloride as a chromogen. Slides were counterstained with hematoxylin and mounted with Permount. Similar stainings for PRL and PCNA were performed using rabbit anti-rat PRL polyclonal antibody (National Hormone and Pituitary Agency) and mouse monoclonal antibody to PCNA (clone PC10; Dako Corp.), at 1:3 and 1:500 dilutions, respectively. Computerassisted image analysis of PCNA-stained slides was performed using the Cell Analysis System-200 (45) with the ER/PR 2.0 version analy- sis software (Becton Dickinson, San Jose, CA), by calculating the mean percentage of cells positively stained and staining intensity, in 15 different fields selected randomly, for each tumor.

Statistical analysis. Results were expressed as mean \pm SEM. Differences were assessed by one-way ANOVA or the unpaired $t$ test, when appropriate. For both statistical tests, $P$ values $<0.05$ were considered significant.

\section{Results}

Transfectant screening. After transfection selected clones were screened for expression of hst. Both GC and GH4 stably transfected cells expressed a 3.6-kb transcript of the human hst cDNA as depicted by Northern blot analysis (Fig. 1, $A$ and $B$ ). Untransfected WT cells and cells transfected with the original pcDNA3 vector did not express this human transcript, while the positive control (F9 embryonal carcinoma cells) expressed a 3.3-kb mRNA transcript which hybridized to the human hst cDNA probe. To test for production of FGF-4, protein immunoprecipitation was performed using an anti-human FGF-4 monoclonal antibody. Cell extracts of GH4 hst transfectants contained hst protein (18-19 kD) (Fig. 2). A less pronounced $\sim 15$-kD band probably represents processed FGF-4 after cleavage of the signal peptide. Untransfected WT GH4 cells,

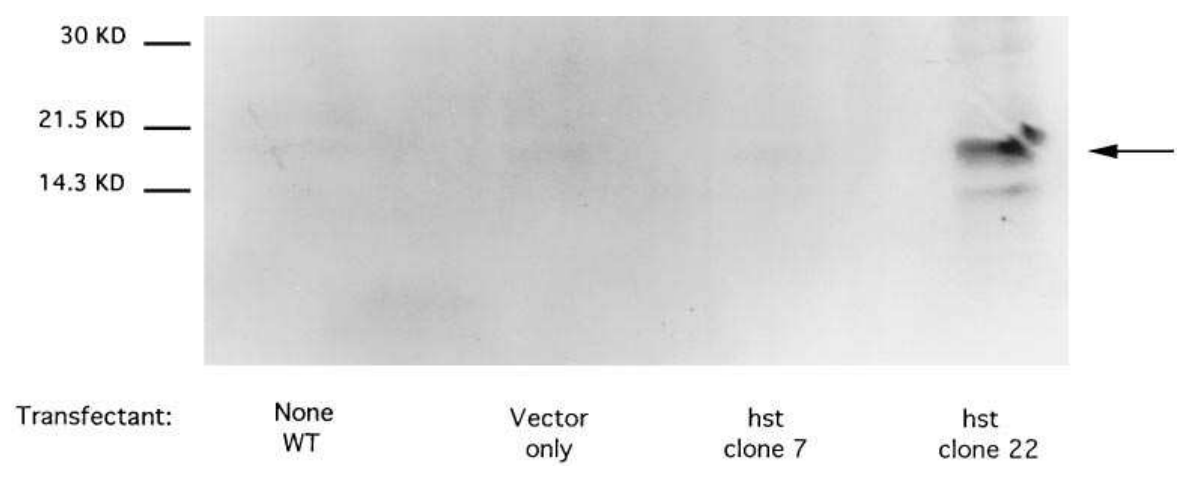

Figure 2. FGF-4 protein immunoprecipitation of GH4 cells stably transfected with human $h s t$ cDNA. Cells were labeled with $500 \mu \mathrm{Ci}$ of $\left[{ }^{35} \mathrm{~S}\right]$ methionine and cysteine, cell extracts were immunoprecipitated with anti-human FGF-4 monoclonal antibody $(8 \mu \mathrm{g} / \mathrm{ml})$, immune complexes were recovered by protein $\mathrm{A}-\mathrm{Sepharose}$ and separated by electrophoresis in a $0.1 \%$ SDS$12.5 \%$ polyacrylamide gel. FGF-4 protein $(18-19 \mathrm{kD})$ is expressed in transfected GH4 cells (clone 22) (arrow) but not in WT cells or cells transfected with the original vector. Clone 7 (transfected with human $h s t$ ) did not express the protein. 


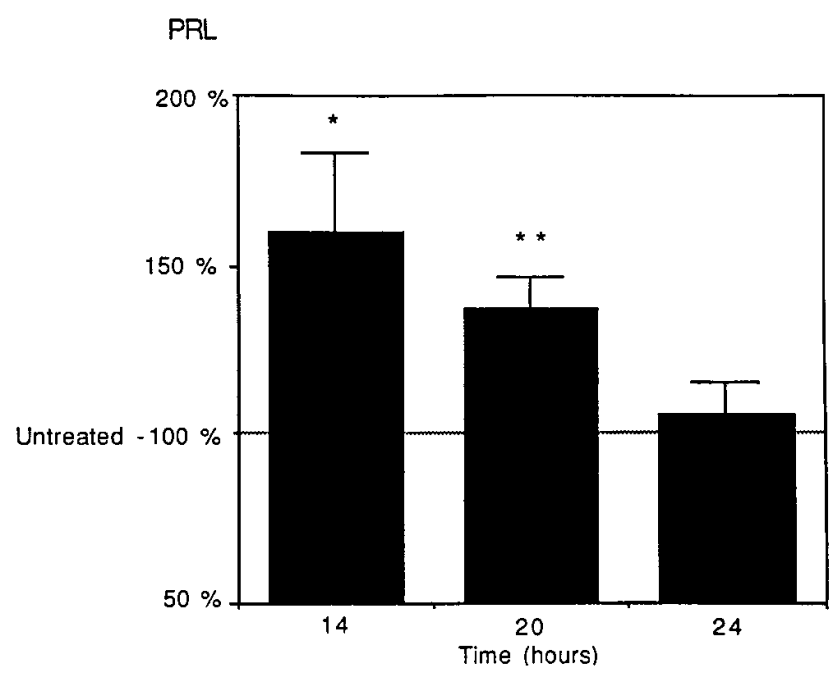

Figure 3. Time-dependent effect of recombinant FGF-4 on PRL secretion by primary cultures of rat anterior pituitary cells harvested from 11 -wk-old Wistar-Furth rats. Cells were seeded $\left(10^{6}\right.$ cells/well $)$ and $24 \mathrm{~h}$ later attached cells in half of the wells were treated with recombinant FGF-4 $(50 \mathrm{ng} / \mathrm{ml})$ in serum-free defined medium for 14, 20 , or $24 \mathrm{~h}$. Each bar represents mean increment ( \pm SEM) of PRL secretion in five to six wells over untreated wells at each time point. $* P<0.05 ; * * P<0.025$.

vector-transfectants, and a nonexpressing clone (clone 7) did not produce this growth factor.

Cell growth and morphology. Both treated WT cells and transfected GH4 cells proliferated faster (20 and 38\% induction of cell growth after $48 \mathrm{~h}$, respectively, $P<0.001$ ), as compared with untreated cells or cells transfected with the original vector alone. In contrast, induction of cell proliferation by $h s t$ was modest in GC cells. Only GC hst transfectants exhibited distinct morphologic changes. These cells changed $48 \mathrm{~h}$ after plating from a rounded WT morphology to a flattened, angu- lar, elongated spindle-shaped morphology and also increased in size. Similar dose-dependent changes were observed within $24 \mathrm{~h}$ of treatment of WT GC cells with added FGF-4. These $h s t$-induced changes were not evident in treated or transfected $\mathrm{GH} 4$ cells.

Hormone secretion. Primary cultures of rat pituitary cells treated with FGF-4 for 14 and $20 \mathrm{~h}$ exhibited increased PRL secretion by $60 \%(P<0.05)$ and $37 \%(P<0.025)$, respectively (Fig. 3). This stimulatory effect was lost when the incubation interval was extended to $24 \mathrm{~h}$. GH release from the primary cells was not altered by the treatment. Because of fibroblast overgrowth in primary cultures induced by the growth factor, further experiments were performed using cell lines, where similar results were obtained. FGF-4 treatment of GH4 cells resulted in a dose-dependent increase of PRL secretion up to 2.5 -fold using a maximal dose of $50 \mathrm{ng} / \mathrm{ml}(P<0.001)$ (Fig. 4 $A)$. In contrast, $\mathrm{GH}$ release decreased by $49 \%(P<0.001)$ in a dose-dependent manner during $48 \mathrm{~h}$ of incubation (Fig. $4 A$ ). Treated GC cells also decreased GH release by $67 \%(P<$ 0.001 ) in a dose-dependent fashion (Fig. $4 B$ ). The GC cells usually do not secrete PRL, and the growth factor did not induce de novo PRL secretion. Stably transfected GH4 cells overexpressing hst also exhibited markedly enhanced basal PRL production in the absence of added FGF-4 (threefold, $P<0.001$ ) (Fig. 5). GH secretion by these cells was not altered after $h s t$ transfection, further indicating the specificity of the PRL induction. Therefore, either added exogenous FGF-4 or endogenously expressed $h s t$ selectively induced PRL secretion while GH was either unaltered or suppressed.

$P R L$ and GH gene transcription. To test the direct effects of hst on PRL and GH gene transcription, GH4 cells were transiently transfected with a chimeric rPRL-luciferase or rGH-luciferase reporter construct and treated with FGF-4. Addition of FGF-4 to transfected cells induced a 3.3-fold induction of PRL promoter-driven luciferase activity (Fig. 6). The stimulation of PRL reporter activity was dose dependent with a maximal effect observed with $50 \mathrm{ng} / \mathrm{ml} \mathrm{FGF-4} \mathrm{(Fig.} 7 A$ )
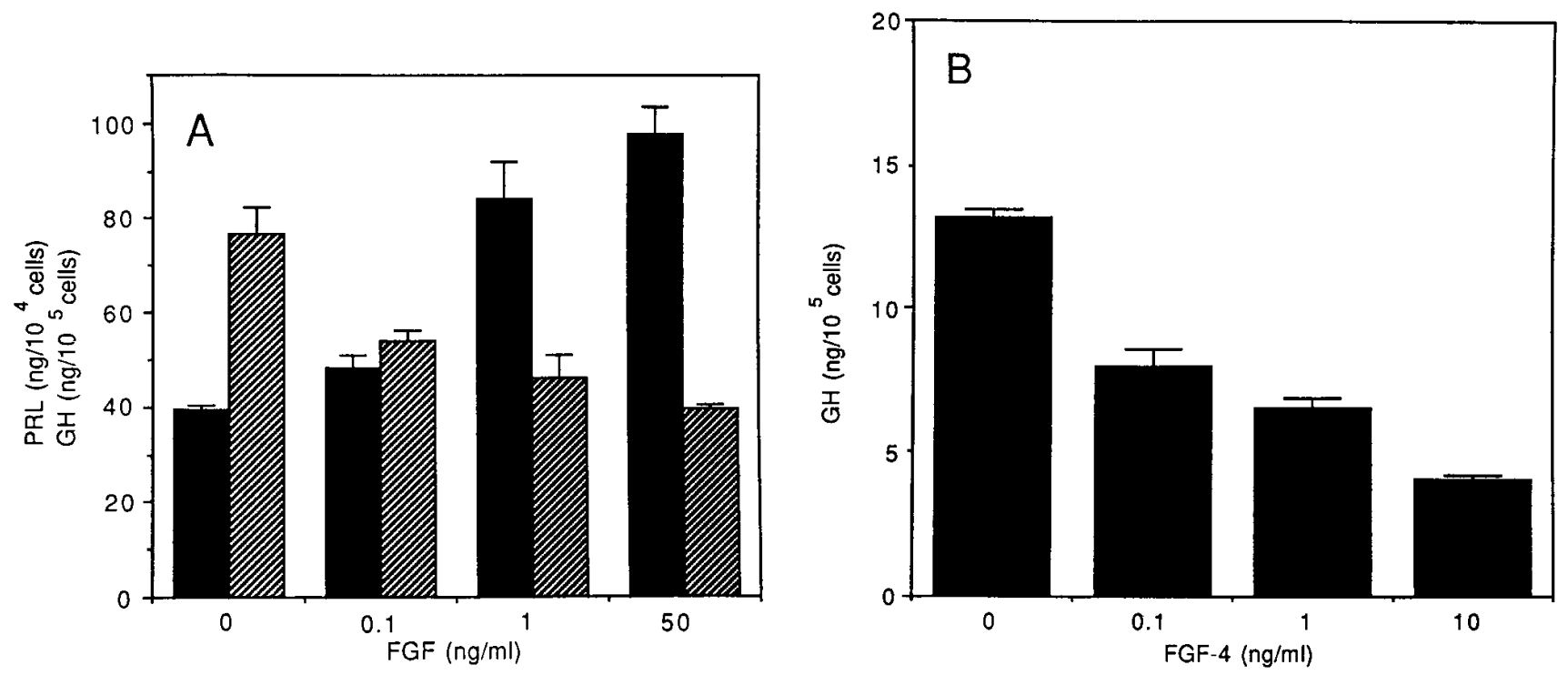

Figure 4. Dose-dependent effects of recombinant FGF-4 on PRL (filled bars) and GH (hatched bars) secretion by GH4 cells ( $A$ ), and on GH secretion by GC cells $(B)$ during $48 \mathrm{~h}$ of incubation. Cells were cultured in serum-free defined medium with the indicated doses of FGF-4. Each bar represents mean \pm SEM of six wells, from a representative experiment performed three times. $P<0.001$ versus untreated wells, both for induction of PRL and reduction of GH. 


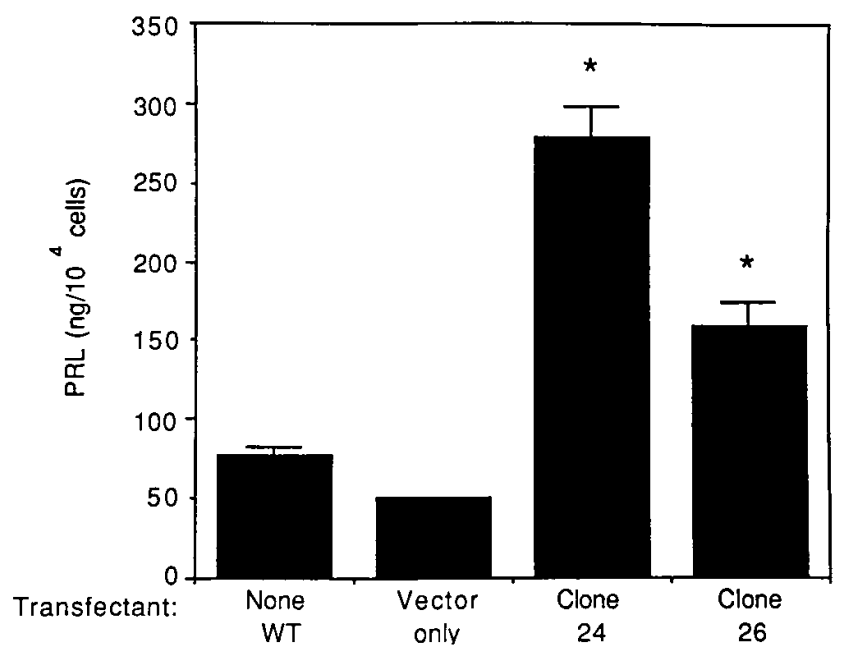

Figure 5. PRL secretion by $h s t$ stable transfectants. GH4 cells were stably transfected with full-length human $h s t$ cDNA and grown for $48 \mathrm{~h}$ in serum containing medium when PRL concentrations were measured. Each bar represents mean \pm SEM of six wells, from a representative experiment repeated twice. ${ }^{*} P<0.001$ versus WT GH4 cells and cells transfected by the vector only.

and time dependent with a maximal effect seen after 9-12 h of treatment with the protein (Fig. 7 B). However, FGF-4 did not alter luciferase activity in cells expressing the $\mathrm{rGH}$ promoterluciferase construct (Fig. 6).

In vivo tumors. To test the effects of hst on in vivo tumor behavior and PRL secretion, stable GH4 and GC hst transfectants were injected subcutaneously to 4-5-wk-old female Wistar-Furth rats. Rats injected with cells transfected with the pcDNA3 vector only served as controls. Only 2 rats (of 5) injected with GH4 control cells produced subcutaneous tumors, compared with 9 of 10 rats injected with hst-transfected GH4 cells. GH4 transfectants induced larger tumors $(2.21 \pm 0.67$ vs. $0.57 \pm 0.35$ grams, $P<0.05)$. In contrast, GC transfectants did not cause enhanced tumor size. Tumors were homogenized, and RNA was extracted for Northern analysis. All the tumors derived from GH4-transfected cells expressed hst mRNA (3.6 $\mathrm{kb}$ ) while control tumors did not contain the transcript (Fig. 8).

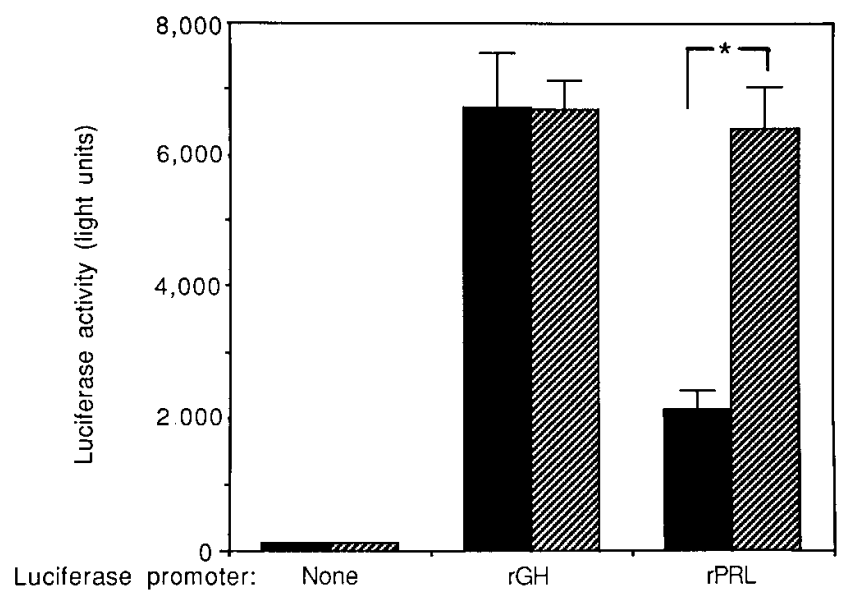

Figure 6. Effect of added FGF-4 protein on PRL and GH transcription in GH4 cells. Cells were transiently transfected with pA3.luc, pA3-425rPRL.luc, or pA3-rGH.luc reporter constructs, and $24 \mathrm{~h}$ later cells in half of the dishes were treated for $9 \mathrm{~h}$ with $50 \mathrm{ng} / \mathrm{ml} \mathrm{FGF-4.}$ Promoter activity is expressed as light emission units integrated over $15 \mathrm{~s}$. Each bar represents mean \pm SEM of six dishes from a representative experiment repeated twice. Filled bars, untreated; hatched bars, FGF-4-treated. $* P<0.001$.

There was no difference between serum GH levels in the control and transfected groups of rats; however, there were modestly higher levels of serum PRL in rats injected with $h s t$-transfected GH4 cells versus control rats injected with vector-only transfectants (57 and 30\% increase, 4 and $5 \mathrm{wk}$ after injection, respectively). Daily cytological examination of vaginal smears in the GH4-injected rats revealed apparent anovulation in $50 \%$ of tumor-bearing rats injected with transfectants $(n=$ $10)$, compared with normal ovarian function seen in all control rats injected with cells not expressing $h s t(n=5)$.

Tumor histology and immunohistochemistry. Tumors derived from $h s t$-expressing GH4 cells exhibited aggressive histologic features compared with control tumors derived from vector-transfected $\mathrm{GH} 4$ cells. These included invasion into surrounding fibro-adipose tissue and skeletal muscle, vascular invasion, high mitotic rate, and extensive tumor necrosis. All tumors revealed cytoplasmic staining for PRL by the immu-
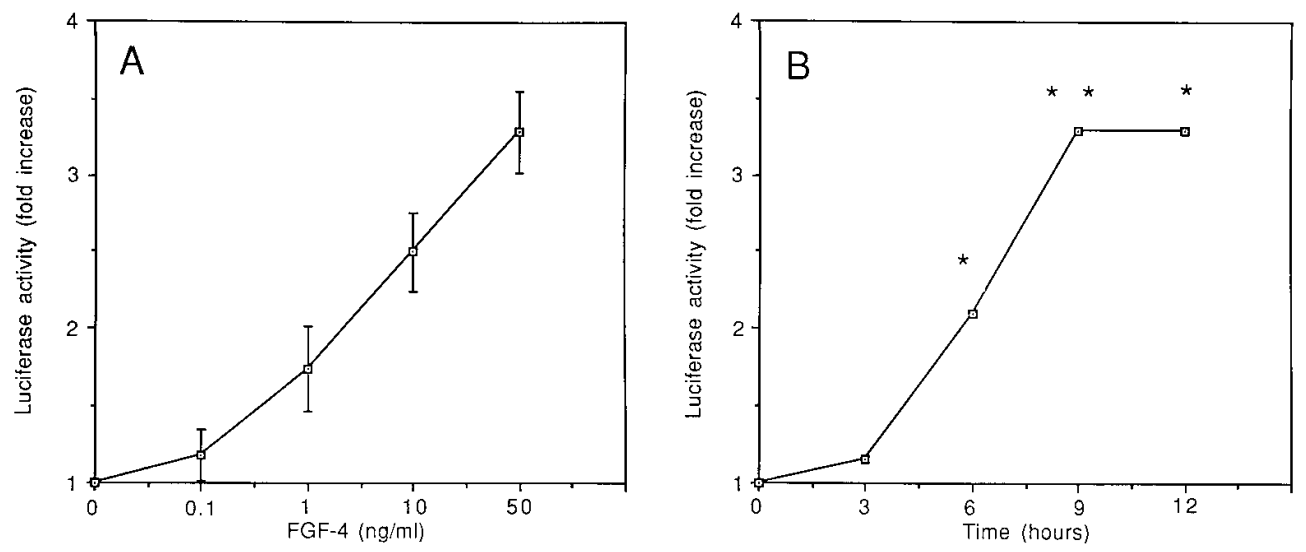

Figure 7. Dose-dependent $(A)$ and time-dependent $(B)$ effects of FGF-4 on rPRL promoter activity in GH4 cells, after transient transfection with pA3425rPRL.luc. Transfected cells were treated for $9 \mathrm{~h}$ with the indicated doses of FGF-4 $(A)$ or for the indicated time intervals with $50 \mathrm{ng} / \mathrm{ml} \mathrm{FGF-4} \mathrm{(B).} \mathrm{The} \mathrm{ef-}$ fect of FGF-4 on promoter activity is expressed as fold induction of light emission integrated over $15 \mathrm{~s}$, compared with untreated cells. Each value represents mean fold increase of luciferase activity in three treated dishes compared with three untreated dishes. (A) $P<0$.001. (B) $* P<$ $0.05 ; * * P<0.01$. 


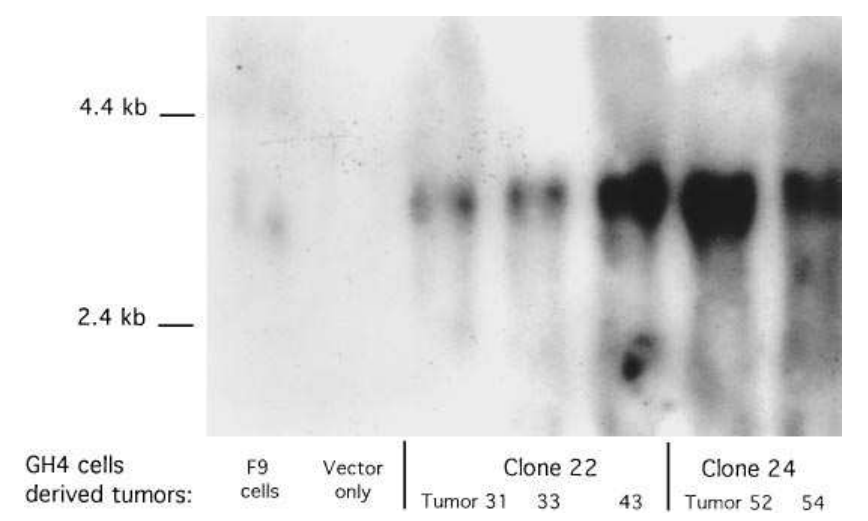

Figure 8. Northern blot of human hst mRNA expression in subcutaneous tumors derived from transfected $\mathrm{GH} 4$ cells injected into 4-5-wk-old female Wistar-Furth rats. $5 \mathrm{wk}$ after injection, rats were killed, tumors were excised and homogenized, and RNA was extracted $(20 \mu \mathrm{g} / \mathrm{lane})$, separated, transferred to nylon membrane, and hybridized with a ${ }^{32} \mathrm{P}$-labeled $\left(\sim 10^{7} \mathrm{cpm}\right) 285$-bp fragment spanning the $3^{\prime}$ half of hst cDNA encoding sequence. RNA derived from tumors transfected with vector only served as negative controls. F9 mouse embryonal carcinoma cells were positive controls. All tumors expressed a $3.6-\mathrm{kb}$ hst transcript.

noperoxidase technique. hst-expressing tumors revealed strong diffuse cytoplasmic staining for FGF-4 protein (Fig. 9). These tumors also revealed increased intensity and percentage of PCNA nuclear staining (by $35 \%, P<0.01$; and $41 \%, P<$ 0.005 , respectively) compared with control tumors (Fig. 9). In contrast, PCNA staining was not different in GC hst transfectants and their respective controls.

\section{Discussion}

This study shows that the hst oncogene and the protein it encodes, FGF-4, induce PRL gene transcription and PRL secretion in GH4 pituitary cells and in primary rat pituitary cell cultures, while FGF-4 reduces GH secretion in the cell line. Transfected $h s t$ cDNA and its encoded protein also induce a transformed morphology in some cells. PRL-secreting subcutaneous tumors derived from transfected GH4 cells expressing hst cDNA and FGF-4 protein were more aggressive and invasive. hst therefore induces PRL gene expression and promotes the neoplastic behavior of pituitary tumors expressing PRL.

hst protooncogene expression is restricted to cells in early stages of development including normal embryonic cells and undifferentiated embryonal carcinoma cells (37), while induction of differentiation in these cells shuts off expression of the gene (18). Mouse and human cell lines and adult tissues do not express $h s t$ mRNA (46). The mechanism of activation of $h s t$ protooncogene to an oncogene is probably due to overexpression rather than to mutations in its FGF-4 coding sequence (25). The overexpressed gene results in the primary translation product, a 206-amino acid growth factor containing a signal peptide sequence, and after glycosylation the mature form of the protein, which is $\sim 30$ amino acids shorter, can be secreted by producer cells. Thus, hst activation and oncogenic behavior are probably due to production and/or secretion of its encoded protein, via an autocrine or paracrine mechanism.

The transfected hst mRNA, detected in GC and GH4 cells, as well as in subcutaneous tumors derived from injected GH4 cells, was $\sim 3.6 \mathrm{~kb}$ long (Figs. 1 and 8) compared with the 3.15-kb-long cDNA inserted into the pcDNA3 expression vector used for stable transfections. This difference can be attributed to transcription of the bovine $\mathrm{GH}$ poly(A) tail, as the transfected cDNA does not contain endogenous poly(A). F9 embryonal carcinoma cells serving as a positive control expressed a 3.3-kb murine mRNA hst transcript using the human hst probe. The murine hst encoding sequence is $82 \%$ homologous to that of human $h s t$ (37) explaining the probe hybridization to the murine mRNA.

hst induction of PRL gene transcription and hormone secretion in GH4 cells as well as PRL induction in primary cell cultures serve as a model to demonstrate the probable role of this oncogene in lactotrope tumor pathogenesis. The 3-fold induction of PRL transcription in GH4 cells after a 9-h incubation with FGF-4 protein accounts for the 2.5 -fold increase of PRL secretion by treated cells and the 3-fold induction of PRL release by cells transfected with $h s t$. The demonstration of the same hormonal effect in primary pituitary cells is of particular importance since it suggests that our observations in pituitary cell lines are physiologically significant. The induction of PRL secretion in primary cultures was lost after $24 \mathrm{~h}$ (Fig. 3). Two possible explanations for this phenomenon are degradation of the growth factor in primary cell culture medium and downregulation of the putative pituitary FGF-4 receptors. Unfortunately, pure cell populations of primary lactotropes are difficult to isolate and their successful transfection has been limited by the presence of multiple primary cell types, which do not replicate in vitro. Nevertheless, the effect of hst on PRL expression in vivo may be even more impressive than the effect achieved in an already transformed cell line or in primary in vitro pituitary cultures. In this study we demonstrate reduction of GH secretion in GH4 and GC cells treated by recombinant FGF-4. The doses used are within the calculated $K_{\mathrm{d}}$ of cellular binding sites for basic FGF $(47,48)$, which probably shares receptors with FGF-4 (11). The preferential production of PRL by $\mathrm{GH} 4$ cells while decreasing $\mathrm{GH}$ expression may illustrate the concomitant stimulatory effect of hst on lactotrope cells while suppressing somatotrope cell activity. However, stable transfectants of both cell lines with hst cDNA did not change GH secretion, compared with control cells, thus highlighting the selectivity of the FGF-4 effect on PRL. Moreover, by using the $\mathrm{rGH}$ promoter $(-528$ to +65 region of $\mathrm{rGH}$ gene) to induce reporter gene activity, FGF-4 did not alter GH transcription in GC and GH4 cells. This may be explained by a possible transcriptional effect of $h s t$ protein through other regulatory elements of the GH gene, located $5^{\prime}$ to the -528 region, or a posttranscriptional mechanism associated with translation or hormonal secretion. The assumption that $h s t$ gene effects are mediated via pathways other than hst protein expression and action is unlikely, considering our knowledge of $h s t$ protooncogene activation (25).

EGF, thyrotropin-releasing hormone (TRH), and basic FGF also stimulate PRL production and inhibit GH synthesis by GH4 cells (49). Basic FGF was also shown to enhance PRL and thyrotropin release from primary cultures of rat anterior pituitary cells, without altering medium GH levels (29). EGF, TRH, and basic FGF induce PRL gene transcription in GH3 cells using 5' PRL genomic sequences $(50,51)$. Recently, it was demonstrated that the hst protein and basic FGF (FGF-2) share tyrosine kinase receptors (11), containing a heparin- 

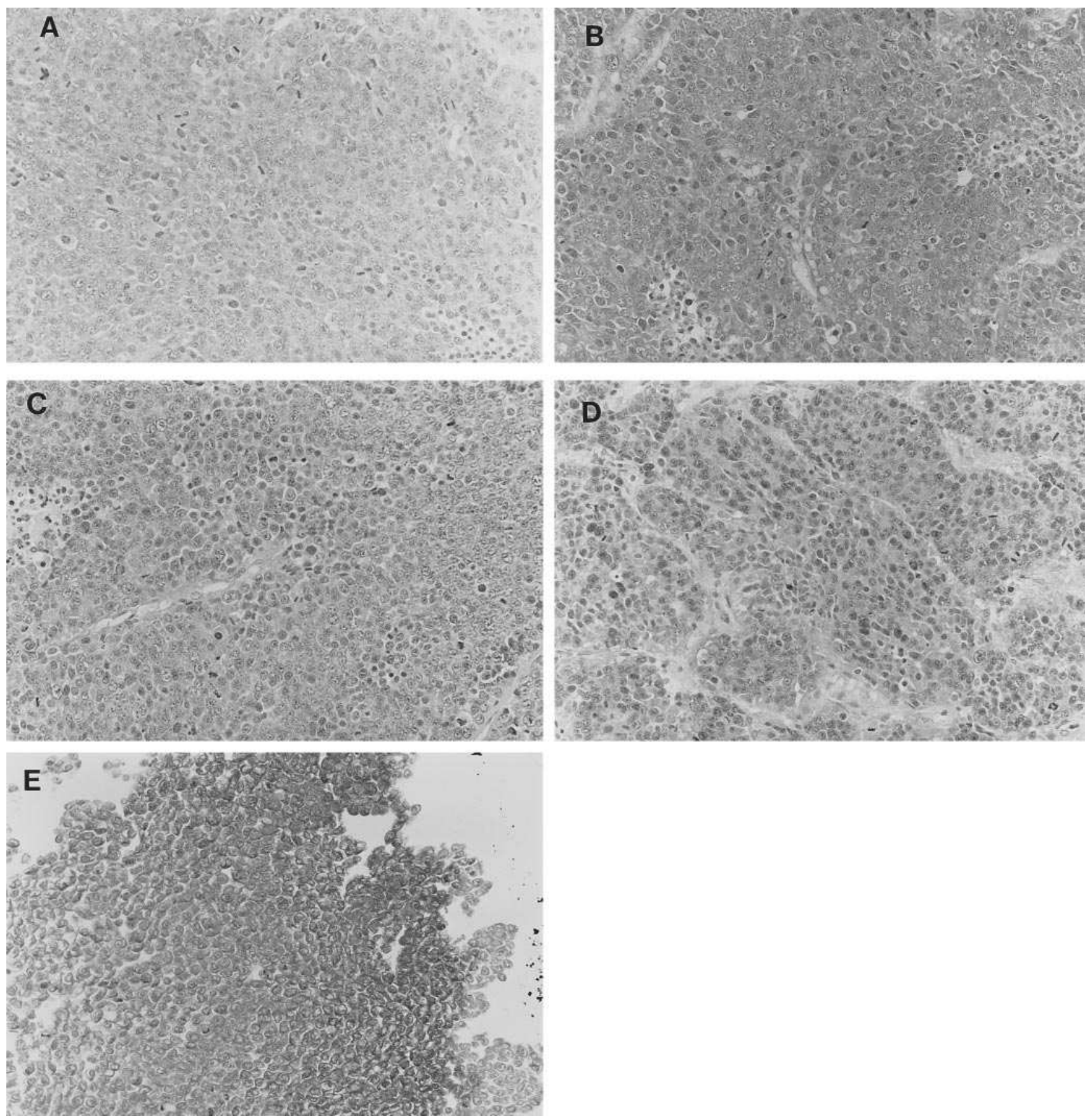

Figure 9. FGF-4 and PCNA immunostaining of subcutaneous tumors derived from injected GH4 cells. ( $A$ ) FGF-4 staining of a tumor derived from cells transfected with vector only (not expressing $h s t$ ). (B) FGF-4 staining of $h s t$-expressing tumor. (C) PCNA-stained tumor transfected with vector only. $(D)$ PCNA-stained tumor derived from $h s t$-transfected cells. $(E)$ F9 embryonal cell carcinoma, immunostained for FGF-4 (positive control).

binding domain (52), which may partially explain their overlapping effects on hormonal regulation in pituitary cells.

hst gene expression and the recombinant FGF-4 protein induced transformed morphology in GC cells. This oncogene was shown previously to cause striking morphological changes in normal NIH $3 \mathrm{~T} 3$ fibroblasts through its secreted protein (15). Similar morphological changes induced by TRH and EGF were reported previously in GH4 cells (49). Of interest, GH4 cells transfected with hst or treated by FGF-4 protein did not portray this transformed phenotype, in contrast to the marked effects of $h s t$ and FGF-4 on hormonal production and cell growth in these cells.

hst modestly induced GH4 cell proliferation. GC cell growth rate was less affected by hst and only a minimal proliferation increment was documented in this cell line, probably due to its more aggressive inherent growth characteristics. In contrast, the growth-promoting activity of $h s t$ protein on NIH 3T3 fibroblasts is more significant (15), while basic FGF was 
shown to decrease cell proliferation of GH4 cells (49). Thus, both the hst gene and the protein it encodes stimulate GH4 cell proliferation; but more significantly, PRL transcription and secretion are induced while concomitantly reducing $\mathrm{GH}$ production. As these cells already are transformed, the $h s t$ gene may have more marked growth-promoting effects in normal pituitary cells.

hst transfection induced in vivo tumor aggressiveness in GH4 transfectants, but not in GC transfectants. $90 \%$ of rats injected with transfected GH4 cells developed tumors that secreted more PRL and suppressed ovarian function. Tumor histology demonstrated invasive and enhanced proliferative characteristics, when compared with tumors not expressing $h s t$. The observation that $h s t$ expression in GH4 cells transformed them to a more aggressive phenotype, combined with a previous observation that human prolactinomas express $h s t$ transforming sequences (33), suggests that this protooncogene may be activated to promote prolactinoma pathogenesis. Moreover, $h s t$ is a potent angiogenic factor $(53,54)$ which may maintain a rich blood supply to neoplastic lactotrope cells (55). In addition, the $h s t$ locus lies in close proximity to the putative MEN-1 locus on chromosome 11q13 (14). As prolactinomas are a common component of MEN-1, this locus may be a potential region for $h s t$ gene activation in sporadic PRL-secreting pituitary tumors.

Our observations provide strong evidence for a common ligand-mediated proximal signal regulating both disordered cell proliferation as well as induced hormone transcription. This linkage demonstrates that the unrestrained hormone secretion characterizing pituitary tumors may not necessarily reflect an increased mass of hormone-secreting cells, but in addition a growth factor-specific induction of polypeptide hormone secretion. Sporadic pituitary adenomas are monoclonal in origin $(2,3)$ and require a multistep process for a clonal cell to form a clinically significant tumor. hst may participate in this process by directly facilitating prolactinoma formation, stimulating their growth, and inducing PRL transcription, via an autocrine or paracrine mechanism.

\section{Acknowledgments}

The authors are grateful to Dr. Hiromi Sakamoto (National Cancer Center Research Institute, Tokyo, Japan) for providing the human hst cDNA; to Dr. Arthur Gutierrez-Hartmann (University of Colorado Health Science Center, Denver, CO) for the rPRL.luc and rGH.luc reporter constructs; and to Grace Labrado for preparing the manuscript.

This work was supported by National Institutes of Health grant DK-42792 (S. Melmed). I. Shimon is a recipient of an American Physician Fellowship.

\section{References}

1. Melmed, S. 1993. Pathogenesis of pituitary tumors. In Molecular Genetics of Nervous System Tumors. A. J. Levine and H. H. Schmidek, editors. Wiley-Liss, Inc., New York. 255-263.

2. Herman, V., J. Fagin, R. Gonsky, K. Kovacs, and S. Melmed. 1990. Clonal origin of secretory and non-secretory pituitary adenomas. J. Clin. Endocrinol. \& Metab. 71:1427-1433.

3. Alexander, J. M., B. M. Biller, H. Bikkai, N. T. Zervas, A. Arnold, and A. Klibanski. 1990. Clinically nonfunctioning pituitary tumors are monoclonal in origin. J. Clin. Invest. 86:336-340.

4. Vallar, L., A. Spada, and G. Giannattasio. 1987. Altered Gs and adenylate cyclase activity in human GH-secreting pituitary adenomas. Nature (Lond.). 330:566-568.

5. Bystrom, C., C. Larsson, C. Blomberg, K. Sandelin, U. Falkmer, B.
Skogseid, K. Oberg, S. Werner, and M. Nordenskjold. 1990. Localization of the MEN1 gene to a small region within chromosome 11q13 by deletion mapping in tumors. Proc. Natl. Acad. Sci. USA. 87:1968-1972.

6. Herman, V., N. Z. Drazin, R. Gonsky, and S. Melmed. 1993. Molecular screening of pituitary adenomas for gene mutations and rearrangements. $J$. Clin. Endocrinol. \& Metab. 77:50-55.

7. Boggild, M. D., S. Jenkinson, M. Pistorello, M. Boscaro, M. Scanarini, P. McTernan, C. W. Perrett, R. V. Thakker, and R. N. Clayton. 1994. Molecular genetic studies of sporadic pituitary tumors. J. Clin. Endocrinol. \& Metab. 78: 387-392.

8. Sakamoto, H., M. Mori, M. Taira, T. Yoshida, S. Matsukawa, K. Shimizu, M. Sekiguchi, M. Terada, and T. Sugimura. 1986. Transforming gene from human stomach cancers and a noncancerous portion of stomach mucosa. Proc. Natl. Acad. Sci. USA. 83:3997-4001.

9. Benharroch, D., and D. Birnbaum. 1990. Biology of the fibroblast growth factor gene family. Isr. J. Med. Sci. 26:212-219.

10. Mason, I. J. 1994. The ins and outs of fibroblast growth factors. Cell. 78: $547-552$.

11. Rifkin, D. B., and D. Moscatelli. 1989. Recent developments in the cell biology of basic fibroblast growth factor. J. Cell Biol. 109:1-6.

12. Taira, M., T. Yoshida, K. Miyagawa, H. Skamoto, M. Terada, and T. Sugimura. 1987. cDNA sequence of human transforming gene hst and identification of the coding sequence required for transforming activity. Proc. Natl. Acad. Sci. USA. 84:2980-2984.

13. Yoshida, T., K. Miyagawa, H. Odagiri, H. Sakamoto, P. F. Little, M. Terada, and T. Sugimura. 1987. Genomic sequence of $h s t$, a transforming gene encoding a protein homologous to fibroblast growth factors and the int-2-encoded protein. Proc. Natl. Acad. Sci. USA. 84:7305-7309.

14. Yoshida, M. C., M. Wada, H. Satoh, T. Yoshida, H. Sakamoto, K. Miyagawa, J. Yokota, T. Koda, M. Kakinuma, T. Sugimura, and M. Terada. 1988 Human HST1 (HSTF1) gene maps to chromosome band 11q13 and coamplifies with the INT2 gene in human cancer. Proc. Natl. Acad. Sci. USA. 85:4861-4864.

15. Delli Bovi, P., A. M. Curatola, F. G. Kern, A. Greco, M. Ittmann, and C. Basilico. 1987. An oncogene isolated by transfection of Kaposi's sarcoma DNA encodes a growth factor that is a member of the FGF family. Cell. 50:729737.

16. Delli Bovi, P., and C. Basilico. 1987. Isolation of a rearranged human transforming gene following transfection of Kaposi sarcoma DNA. Proc. Natl. Acad. Sci. USA. 84:5660-5664.

17. Adelaide, J., M. G. Mattei, I. Marics, F. Raybaud, J. Planche, O. D. Lapeyriere, and D. Birnbaum. 1988. Chromosomal localization of the hst oncogene and its co-amplification with the int-2 oncogene in human melanoma. $\mathrm{On}$ cogene. 2:413-416.

18. Velcich, A., P. Delli-Bovi, A. Mansukhani, E. B. Ziff, and C. Basilico. 1989. Expression of the K-fgf protooncogene is repressed during differentiation of F9 cells. Oncogene Res. 5:31-37.

19. Nakagama, H., S. Ohnishi, M. Imawari, H. Hirai, F. Takaku, H. Sakamoto, M. Terada, M. Nagao, and T. Sugimura. 1987. Identification of transforming genes as hst in DNA samples from two human hepatocellular carcinomas. Jpn. J. Cancer Res. 78:651-654.

20. Tsuda, T., H. Nakatani, T. Matsumura, K. Yoshida, E. Tahara, T. Nishihira, H. Sakamoto, T. Yoshida, M. Terada, and T. Sugimura. 1988. Amplification of the hst-1 gene in human esophageal carcinomas. Jpn. J. Cancer Res. 79: 584-588.

21. Strohmeyer, T., S. Peter, M. Hartmann, S. Munemistu, R. Ackermann, A. Ullrich, and D. J. Slamon. 1991. Expression of the hst-1 and c-kit protooncogenes in human testicular germ cell tumors. Cancer Res. 51:1811-1816.

22. Talarico, D., and C. Basilico. 1991. The K-fgf/hst oncogene induces transformation through an autocrine mechanism that requires extracellular stimulation of the mitogenic pathway. Mol. Cell. Biol. 11:1138-1145.

23. Feldman, B., W. Poueymirou, V. E. Papaioannou, T. M. DeChiara, and M. Goldfarb. 1995. Requirement of FGF-4 for postimplantation mouse development. Science (Wash. DC). 267:246-249.

24. Niswander, L., S. Jeffrey, G. R. Martin, and C. Tickle. 1994. A positive feedback loop coordinates growth and patterning in the vertebrate limb. Nature (Lond.). 371:609-612.

25. Delli Bovi, P., A. M. Curatola, K. M. Nweman, Y. Sato, D. Moscatelli, R. M. Hewick, D. B. Rifkin, and C. Basilico. 1988. Processing, secretion, and biological properties of a novel growth factor of the fibroblast growth factor family with oncogenic potential. Mol. Cell. Biol. 8:2933-2941.

26. Gospodarowicz, D. 1975. Purification of a fibroblast growth factor from bovine pituitary. J. Biol. Chem. 250:2515-2520.

27. Bohlen, P., A. Baird, F. Esch, N. Ling, and D. Gospodarowicz. 1984 Isolation and partial molecular characterization of pituitary fibroblast growth factor. Proc. Natl. Acad. Sci. USA. 81:5364-5368.

28. Li, Y., M. Koga, S. Kasayama, K. Matsumoto, N. Arita, T. Hayakawa, and B. Sato. 1992. Identification and characterization of high molecular weigh forms of basic fibroblast growth factor in human pituitary adenomas. J. Clin. Endocrinol. \& Metab. 75:1436-1441.

29. Baird, A., P. Mormede, S. Y. Ying, W. B. Wehrenberg, N. Ueno, N. Ling, and R. Guillemin. 1985. A nonmitogenic pituitary function of fibroblast growth factor: regulation of thyrotropin and prolactin secretion. Proc. Natl. Acad. Sci. USA. 82:5545-5549. 
30. Atkin, S. L., A. M. Landolt, R. V. Jeffreys, M. Diver, J. Radcliffe, and M. C. White. 1993. Basic fibroblast growth factor stimulates prolactin secretion from human anterior pituitary adenomas without affecting adenoma cell proliferation. J. Clin. Endocrinol. \& Metab. 77:831-837.

31. Zimering, M. B., M. L. Brandi, D. A. deGrange, S. J. Marx, E. Streeten, N. Katsumata, P. R. Murphy, Y. Sato, H. G. Friesen, and G. D. Aurbach. 1990. Circulating fibroblast growth factor-like substance in familial multiple endocrine neoplasia type 1. J. Clin. Endocrinol. \& Metab. 70:149-154.

32. Zimering, M. B., N. Katsumata, Y. Sato, M. L. Brandi, G. D. Aurbach, S. J. Marx, and H. G. Friesen. 1993. Increased basic fibroblast growth factor in plasma from multiple endocrine neoplasia type 1 : relation to pituitary tumor. $J$. Clin. Endocrinol. \& Metab. 76:1182-1187.

33. Gonsky, R., V. Herman, S. Melmed, and J. Fagin. 1991. Transforming DNA sequences present in human prolactin-secreting pituitary tumors. Mol. Endocrinol. 5:1687-1695.

34. Sanger, F., S. Nicklen, and A. R. Coulson. 1977. DNA sequencing with chain-termination inhibitors. Proc. Natl. Acad. Sci. USA. 74:5463-5467.

35. Felgner, P. L., T. R. Gadek, M. Holm, R. Roman, H. W. Chan, M. Wenz, J. P. Northrop, G. M. Ringold, and M. Danielsen. 1987. Lipofectin: a highly efficient, lipid-mediated DNA-transfection procedure. Proc. Natl. Acad. Sci. USA. 84:7413-7417.

36. Chomczynski, P., and N. Sacchi. 1987. Single step method of RNA isolation by acid guanidinium thiocyanate-phenol-chloroform extraction. Anal. Biochem. 162:156-159.

37. Brooks, S., R. Smith, J. Thurlow, C. Dickson, and G. Peters. 1989. The mouse homologue of $h s t / k$-FGF: sequence, genome organization and location relative to int-2. Nucleic Acids Res. 17:4037-4045.

38. Akita, S., J. Webster, S. G. Ren, H. Takino, J. Said, O. Zand, and S. Melmed. 1995. Human and murine pituitary expression of leukemia inhibitory factor. Novel intrapituitary regulation of adrenocorticotropin hormone synthesis and secretion. J. Clin. Invest. 95:1288-1298.

39. Prager, D., H. Yamasaki, M. M. Weber, S. Gebremedhin, and S. Melmed. 1992. Human insulin-like growth factor I receptor function in pituitary cells is suppressed by a dominant negative mutant. J. Clin. Invest. 90:2117-2122.

40. de Wet, J. R., K. V. Wood, M. DeLuca, D. R. Helinski, and S. Subramani. 1987. Firefly luciferase gene: structure and expression in mammalian cells. Mol. Cell. Biol. 7:725-737.

41. Rugh, R. 1990. The Mouse-Its Reproduction and Development. Oxford University Press, Oxford. 38-39.

42. Hall, P. A., D. A. Levinson, A. L. Woods, C. C. Yu, D. B. Kellock, J. A. Watkins, D. M. Barnes, C. E. Gillett, R. Camplejohn, R. Dover, et al. 1990. Proliferating cell nuclear antigen (PCNA) immunolocalization in paraffin sections: an index of cell proliferation with evidence of deregulated expression in some neoplasms. J. Pathol. 162:285-294.
43. Sebo, T. J., P. C. Roche, T. E. Witzig, and P. J. Kurtin. 1993. Proliferative activity in non-Hodgkin's lymphomas. A comparison of the bromodeoxyuridine labeling index with PCNA immunostaining and quantitative image analysis. Am. J. Clin. Pathol. 99:668-672.

44. Pinkus, G. S., J. L. Pinkus, N. S. Goldstein, I. P. Shintaku, and J. W. Said. 1995. A putative marker for B cell proliferations-staining profile of 426 paraffin-embedded tissues. Appl. Immunohistochem. 3:23-31.

45. Bacus, S., J. L. Flowers, M. F. Press, J. W. Bacus, and K. S. McCarty, Jr. 1988. The evaluation of estrogen receptor in primary breast carcinoma by computer-assisted image analysis. Am. J. Clin. Pathol. 90:233-239.

46. Basilico, C., K. M. Newman, A. M. Curatola, D. Talarico, A. Mansukhani, A. Velcich, and P. Delli-Bovi. 1989. Expression and activation of the K-fgf oncogene. Ann. NY Acad. Sci. 567:95-103.

47. Neufeld, G., and D. Gospodarowicz. 1985. The identification and partial characterization of the fibroblast growth factor receptor of baby hamster kidney cells. J. Biol. Chem. 260:13860-13868.

48. Moscatelli, D. 1987. High and low affinity binding sites for basic fibroblast growth factor on cultured cells: absence of a role for low affinity binding in the stimulation of plasminogen activator production by bovine capillary endothelial cells. J. Cell. Physiol. 131:123-130.

49. Schonbrunn, A., M. Krasnoff, J. M. Westendorf, and A. H. Tashjian, Jr. 1980. Epidermal growth factor and thyrotropin-releasing hormone act similarly on a clonal pituitary cell strain. J. Cell Biol. 85:786-797.

50. Supowit, S. C., E. Potter, R. M. Evans, and M. G. Rosenfeld. 1984. Polypeptide hormone regulation of gene transcription: specific $5^{\prime}$ genomic sequences are required for epidermal growth factor and phorbol ester regulation of prolactin gene expression. Proc. Natl. Acad. Sci. USA. 81:2975-2979.

51. Berwaer, M., P. Monget, B. Peers, M. Mathy-Hartert, E. Bellefroid, J. R. Davis, A. Belayew, and J. A. Martial. 1991. Multihormonal regulation of the human prolactin gene expression from $5000 \mathrm{bp}$ of its upstream sequence. Mol. Cell. Endocrinol. 80:53-64.

52. Kan, M., F. Wang, J. Xu, J. W. Crabb, J. Hou, and W. L. McKeehan. 1993. An essential heparin-binding domain in the fibroblast growth factor receptor kinase. Science (Wash. DC). 259:1918-1921.

53. Miyagawa, K., H. Sakamoto, T. Yoshida, Y. Yamashita, Y. Mitsui, M. Furusawa, S. Maeda, F. Takaku, T. Sugimura, and M. Terada. 1988. hst-1 transforming protein: expression in silkworm cells and characterization as a novel heparin-binding growth factor. Oncogene. 3:383-389.

54. Yoshida, T., K. Ishimaru, H. Sakamoto, J. Yokota, S. Hirohashi, K. Igarashi, K. Sudo, and M. Terada. 1994. Angiogenic activity of the recombinant hst-1 protein. Cancer Lett. 83:261-268.

55. Schechter, J., P. Goldsmith, C. Wilson, and R. Weiner. 1988. Morphological evidence for the presence of arteries in human prolactinomas. J. Clin. Endocrinol. \& Metab. 67:713-719. 